Article

\title{
Long-Term Assessment of Selective Pruning of Quercus Species for Controlling Populations of Coraebus florentinus (Coleoptera: Buprestidae) in Mediterranean Forests
}

\author{
Patricia Gallardo * (D), Ana M. Cárdenas and Juan M. Soriano \\ Department of Zoology, University of Cordoba, Cordoba 14005, Spain; ba1cataa@uco.es (A.M.C.); \\ jsorianomunoz.86@gmail.com (J.M.S.) \\ * Correspondence: b42gatop@uco.es; Tel.: +34-957-218604
}

Received: 20 December 2017; Accepted: 19 January 2018; Published: 23 January 2018

\begin{abstract}
Coraebus florentinus (Herbst) is one of the most important wood borer pests damaging oak species in Mediterranean forests. Recently, the effect of temperature on the pre-imaginal development of this insect was established, and predictive models of survival and emergence in relation to temperature were performed, which allow scheduled management techniques to be fit in accordance with the biological timing of this species. In this study, the effect of selective pruning of damaged branches of Quercus species for controlling the population of this insect is assessed. The study was carried out in three plots located in the Sierra Morena Mountains (southern Iberian Peninsula). In each plot, forest features were typified, and the parameters "infestation level" and "population intensity" were quantified. The assessment was performed one year and five years after applying selective pruning. The most effective time to prune was established according to the predictive model mentioned above. After one year, the results indicated that selective pruning just before adult emergence was effective in reducing the population size and controlling damage. After five years, this effect was still significantly manifested. In addition, the results show that selective pruning is effective even in areas with lower initial rates of infestation.
\end{abstract}

Keywords: Buprestidae; Coraebus florentinus; Mediterranean forests; oak; Quercus; selective pruning; wood borer insects

\section{Introduction}

Coraebus florentinus (Herbts, 1801) (Coleoptera: Buprestidae), commonly known as black-banded oak borer, is a wood borer beetle causing drying and subsequent death of branches of mostabundant Quercus species growing in the Mediterranean Region [1]. Therefore, it is not a very aggressive pest and, originally, it had restricted distribution to Mediterranean forests, where cork and evergreen oaks predominate [2].

Damage is the result of the larval feeding activity, which, at the beginning of its development, bores longitudinal galleries beneath the bark of young and healthy branches. At the end of the larval stage, the insect changes its boring direction, turning in the gallery and interrupting the sap flow. This causes the death of the branch upon completion of metamorphosis [3,4].

Because larval development is entirely endophytic and the tree does not show initial signs of infestation, control treatments with phytosanitary products are impractical. In fact, there are no specific insecticides for the black-banded oak borer registered in Spain. Moreover, insecticides would contaminate the cork, risking human health. This is why current research aims to obtain attractants for the capture of adults (chromatic traps, pheromones, or aggregation compounds) and to develop an environmentally friendly approach to control this pest related to the chemical ecology of 
C. florentinus [4]. Studies have revealed that odours released by males and females are qualitatively and quantitatively similar, but behavioural assays have demonstrated that the antennae of males are more sensitive to beetle-produced volatiles than those of females [4]. Even if these control procedures were fully developed, it would be difficult to accurately apply them due to the extent of their mature period, along with the shortage of the adult life [5]. In addition, biological control techniques have been explored, i.e., populations of $C$. florentinus could be slightly controlled with natural enemies (Picusviridis L.; Xylophoruscoraebi Thomson; Atanycolus sculpturatus Thomson; Cerceris bupresticida Thomson) [6].

Nevertheless, the most effective method to control this pest to date consists of pruning and subsequent removal of damaged branches $[1,5,7,8]$. This procedure is valid, provided that the branch is cut when the insect has reached the pupa stage, which coincides with the symptomatic manifestation of damage in the branch (first pallor and then redness and dryness of leaves) [5], and is prior to the emergence, dispersion, and reproduction of the adult.

Recent studies dealing with the influence of temperature on the development of this borer have performed predictive models based on the establishment of temperature intervals that induce the optimal progression from pupae to adult. These models allow scheduled management techniques to be fitted with the biological timing of this species, according to the inter-annual thermic variability [1,9]. Previously, other authors recommended pruning as a control method in areas with high levels of infestation $(\approx 90 \%)$ [5], but they did not fit the pruning time to the lifecycle of $C$. florentinus. Prior to applying selective pruning, it is necessary to know the effectiveness of the procedure on the course of the insect populations as well as the impact on the next generations.

Taking into account the abovementioned information, the present study was proposed with the objective of designing, executing, and assessing the long-term effectiveness of a management plan consisting of selective pruning of affected branches and the subsequent quantification of C. florentinus populations.

\section{Materials and Methods}

\subsection{The Area}

Sampling was performed in the Hornachuelos Natural Park, Sierra Morena Mountains (southern Iberian Peninsula) (Figure 1), where the landscape is dominated by Mediterranean mixed sclerophyllous forests. The most representative woodland species are Q. ilex subsp. Ballota L.; Q. suber L.; Q. faginea, Lam.; P. istacialentiscus L.; Asparagus albus L.; Erica australis L.; and different species of Cistus (C. ladanifer L., C. crispus L., C. monspeliensis L., C. salviifolius L., and C. albidus L.) in the shrubland $[10,11]$.

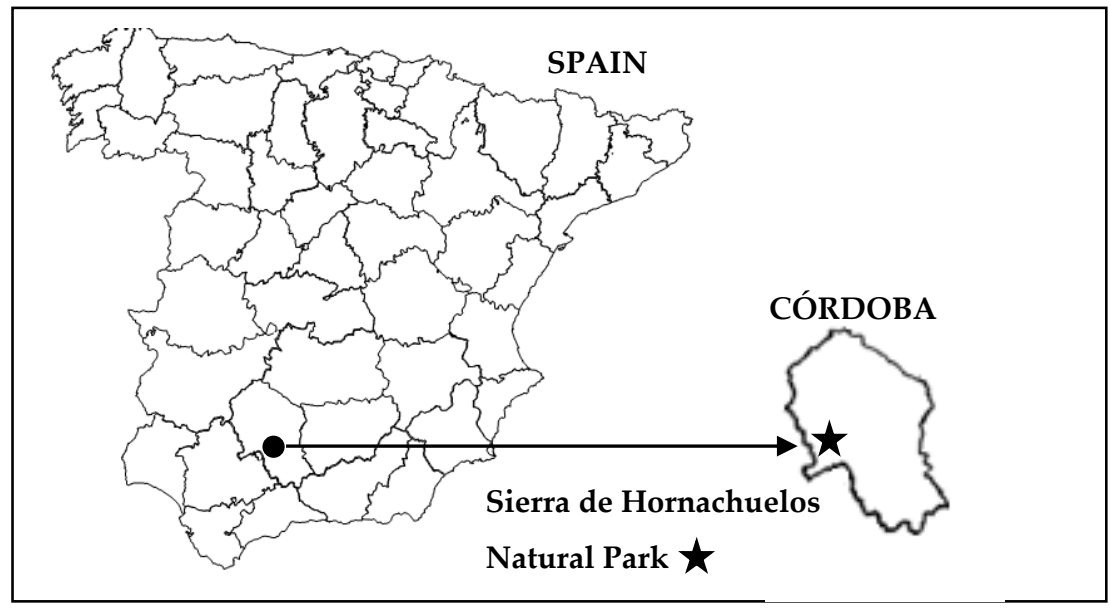

Figure 1. Location of the research area [10]. 


\subsection{Field Work}

Field work was carried out in three plots named "Los Lagares", "Mezquitillas" and "El Patriarca" (P1, P2 and P3, respectively), where previously different levels of damage caused by C. florentinus had been quantified $[9,12]$. In each plot, two areas of approximately 1.5 ha and similar environmental features and damage level by $C$. florentinus were delimited and selected for sampling. The main environmental features of each plot (altitude, orientation, orography, surface, vegetal composition and coverage, tree density, and woodland age) and the level of damage are summarised in Appendix (Tables A1-A3). In each area, 100 trees (mainly Q. ilex, but also Q. suber and Q. faginea in minor proportions) were selected and geo-referenced. In one of the areas (selective pruning area), besides assessing damage, all the branches damaged by the buprestid were pruned and removed. In the other area (control area), infestation was evaluated, but no pruning treatment was done. In addition, in both the selective pruning area and control area, a ring around the perimeter of about $35 \mathrm{~m}$ wide (34.53 $\mathrm{m} \pm 3.88$ S.D.) was considered for assessing damage by C. florentinus (areas of influence), because its infestation could be decisive for possible re-invasions of the insect (Figures 2 and 3). The amplitude of this area was established while taking into account the tree density and that C. florentinus is a slow-flying beetle, with almost vertical trajectory and very short distances in flight movements [5]. In each area of influence, 100 trees were also selected to evaluate damage.

The amplitude of the perimeter in each area of influence varied depending on the orography and the terrain constraints. To discard significant differences on the extent of the 12 areas of influence, 10 measurements were taken for each, and data were analysed by one-way ANOVA statistic. Results $(P=0.268 ; F=1.368)$ indicated no significant differences, validating the experimental design.

Based on the temperature/emergence predictive model of Cárdenas \& Gallardo [1], pruning was carried out after mid-April 2012, coinciding with the pupation phase and the time when the environmental temperature reached the optimum threshold for the development of this stage (Table A4). Data on environmental temperatures were obtained from the website of the Agriculture and Fisheries Council, of the Junta de Andalucía, Spain [13].

Once the branches were diagnosed by visual surveying, they were sawed (with $4.5 \mathrm{~m}$ pole scissors) just below the pupation chamber, which is easily recognisable by the superficial thickening surrounding it [14]. Diagnosis was made by observing the branches that showed clear symptoms of suffering a recent attack (yellowish leaves still in the treetop) [4], well differentiable from those infected in previous years (few, obscure, and dry leaves still hanging on the branch, or the branches are totally defoliated, acquiring a singular aspect, recognizable on the canopy $[15,16])$.

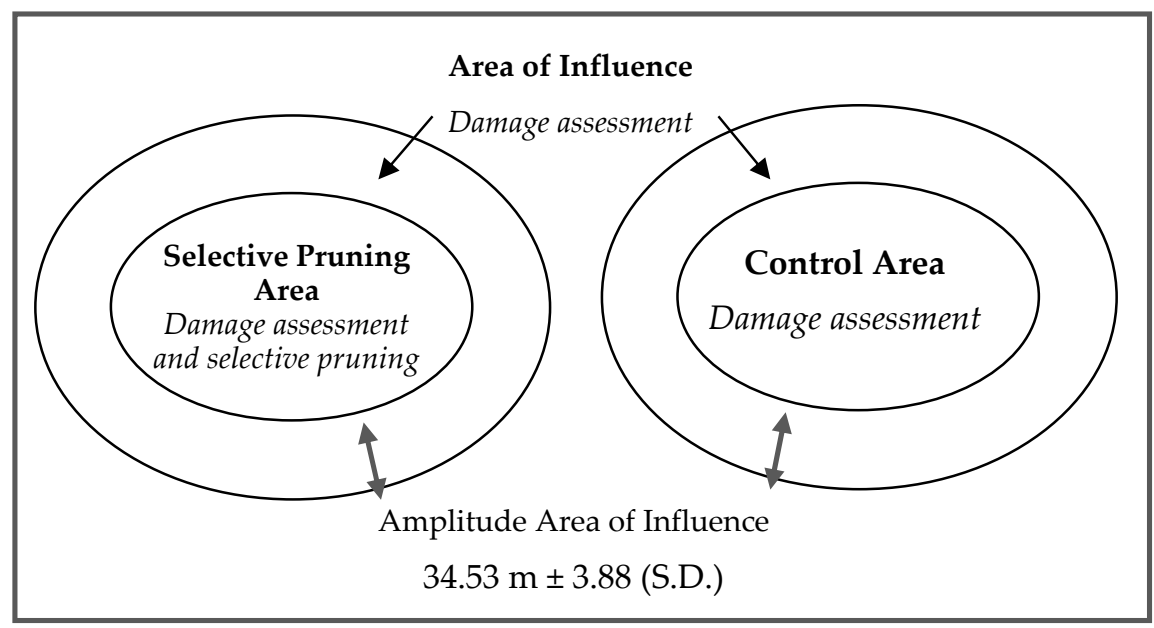

Figure 2. Schematic representation of the different sampling areas and study plots and their respective tasks completed in 2012. 


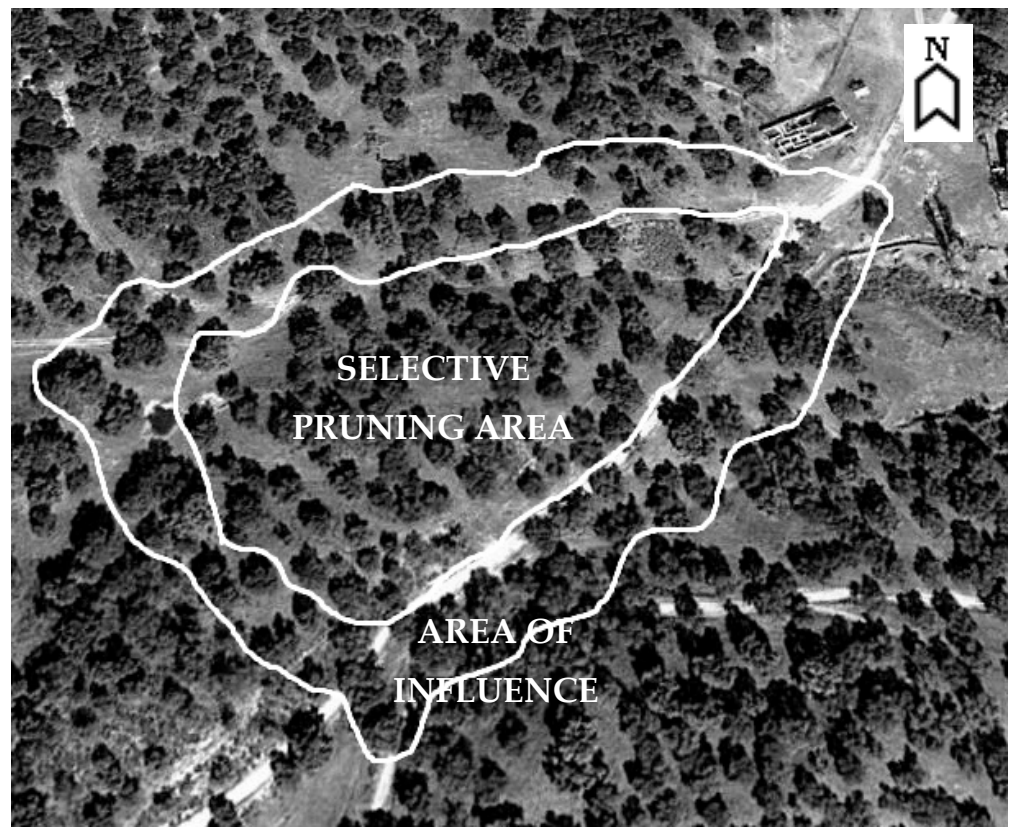

Figure 3. Orthophoto showing one of the Selective Pruning Areas and its Area of Influence.

During the months of May to July 2012, the infestation by the buprestid was evaluated in all control zones and areas of influence (Table 1). In the spring of 2013 and 2017, systematic tree prospections of all the areas were carried out to evaluate again the damages caused by $C$. florentinus and to assess the efficacy of selective branch pruning in the short and long term (Table 1).

Table 1. Schedule of activities carried out in each of the zones established for each plot during the three years of sampling.

\begin{tabular}{|c|c|c|c|c|c|c|}
\hline \multirow{3}{*}{ Years of Sampling } & \multicolumn{6}{|c|}{ Dates of Sampling } \\
\hline & \multicolumn{3}{|c|}{ Selective Pruning Area } & \multicolumn{3}{|c|}{ Area of Influence } \\
\hline & P1 & P2 & P3 & P1 & P2 & P3 \\
\hline 2012 & 16 April * & 26 April * & 20 April * & 10 July & 10 July & 10 July \\
\hline 2013 & 27 May & 27 May & 14 May & 11 June & 10 June & 14 May \\
\hline 2017 & 9 June & 15 June & 23 May & 9 June & 15 June & 23 May \\
\hline \multirow{2}{*}{ Years of Sampling } & \multicolumn{3}{|c|}{ Control Area } & \multicolumn{3}{|c|}{ Area of Influence } \\
\hline & P1 & P2 & P3 & P1 & P2 & P3 \\
\hline 2012 & 12 June & 19 May & 9 May & 10 July & 12 June & 9 May \\
\hline 2013 & 20 June & 28 June & 23 May & 28 June & 12 July & 23 May \\
\hline 2017 & 9 June & 15 June & 30 May & 9 June & 15 June & 30 May \\
\hline
\end{tabular}

The asterisk $\left({ }^{*}\right)$ indicates the selective pruning dates.

\subsection{Data Analysis}

To evaluate damage by C. florentinus, the following parameters were estimated: Infestation level (IL), defined as the proportion of trees damaged from the total sampled; and Population intensity (PI), or average number of dry branches per damaged tree.

The independent sample $T$-test was used to check differences in PIs of each area over different monitoring years. If the normality assumptions were not satisfied, after checking by the Shapiro-Wilk test, the equivalent non-parametric Mann-Whitney U/Wilcoxon Ranked Sum test was performed [17]. 
Analysis of variance (one-way ANOVA) was used to test for differences in PIs among different plots and also among the areas in each plot. The assumptions of normality and homoscedasticity were checked with the Shapiro-Wilk test and Levene test, respectively [17]. If the data did not satisfy the normality and homoscedasticity criteria, the non-parametric Kruskal-Wallis test was applied instead.

To explore relationships between IL and PI in different plots, areas, and years of sampling, a Generalized Lineal Mixed Model (GLMM) was performed using the information criteria to check for GLMM inference. This information-theoretic method quantifies the magnitude of difference between models in expected predictive power [18]. Both the Akaike and the Bayesian information criteria have been considered for interpreting the results. The statistical tests were performed using SPSS (20.0, International Business Machines Corporation, NY, USA) [19].

\section{Results}

\subsection{Initial Incidence of Coraebus florentinus: Analysis of the Starting Situation}

Data on ILs and PIs obtained in 2012 in the four sampling areas (pruning area, control area, and their respective areas of influence) established at each sampling plot are recorded in Table 2. It was observed that ILs in the areas selected in plots P1 and P2 were quite similar, with percentages of damaged trees ranging between 10\% and 18\%. Nevertheless, in P3 the ILs were much higher than those of the other plots, with a percentage between $24 \%$ and $34 \%$. Regarding the PI, a statistical comparison did not find significant differences in any of the cases considered, neither among the sampling plots $\left(P=0.789 ; \chi^{2}=0.346 ; \alpha \leq 0.05\right)$ nor among the different areas within each plot (P1: $\left.P=0.146, x^{2}=5.379 ; \mathrm{P} 2: P=0.607, x^{2}=1.835 ; \mathrm{P} 3: P=0.863, x^{2}=0.745\right)$.

Table 2. Values of Infestation Level (IL) in \%, and Population Intensity (PI) in average number of dry branches/tree, corresponding to each sampling area established inside each sampling plot (P1, P2, and P3) in 2012.

\begin{tabular}{ccccccc}
\hline \multirow{2}{*}{ Sampling Plots 2012 } & \multicolumn{2}{c}{ P1 } & \multicolumn{2}{c}{ P2 } & \multicolumn{2}{c}{ P3 } \\
\cline { 2 - 7 } & IL & PI & IL & PI & IL & PI \\
\hline Pruning Area & 12 & 1.25 & 14 & 1.64 & 34 & 1.26 \\
Area of Influence of Pruning Area & 18 & 1.23 & 10 & 1.20 & 24 & 1.29 \\
Control Area & 17 & 1.41 & 15 & 1.20 & 32 & 1.41 \\
Area of Influence of Control Area & 11 & 1.72 & 11 & 1.36 & 27 & 1.34 \\
\hline
\end{tabular}

Related to the relationships between IL and IP, the values provided by the GLMM analysis for the verisimilitude log are lower than those of the information criteria (Table A5). Thus, no good fit can be inferred, and no relation could be supported from it.

\subsection{Incidence of Coraebus florentinus One Year after Selective Pruning: Short-Term Infestation}

To determine the effect of selective pruning one year after treatment, we again assessed the parameters in consideration for this study (ILs and PIs) and then made a comparison with respect to the previous year. In 2013, the values of ILs corresponding to the pruning areas were approximately half of those in the control areas. Ostensive differences and lower values were also observed with respect to their areas of influence. This result is generalizable for the three sampling plots (Table 3). On the contrary, the PIs were quite alike. In fact, the statistical tests performed to contrast the appraisal results were not significant among the sampling plots $\left(P=0.098 ; x^{2}=4.646 ; \alpha \leq 0.05\right)$ or the different areas within each plot $\left(\mathrm{P} 1: \mathrm{P}=0.701, x^{2}=1.421\right.$; P2: $P=0.301, x^{2}=3.655$; P3: $\left.P=0.918, x^{2}=0.504\right)$.

Comparing the ILs recorded in 2012 and 2013, a noticeable reduction was perceived, close to 50\%, in the three pruning areas, while values were similar in the control areas. In addition, a downward trend was found in the LIs registered in the areas of influence linked to the pruning areas. However, these levels remained similar or slightly higher in the control areas and their perimeters of influence. 
The analysis of variations in the distribution of $C$. florentinus populations resulting from the comparison of inter-annual data of PIs revealed no significant changes in the established probabilistic framework (Table 4).

Table 3. Values of Infestation Level (IL) in \%, and Population Intensity (PI) in average number of dry branches/tree, corresponding to each sampling area established inside each sampling plot (P1, P2, and P3) in 2013.

\begin{tabular}{ccccccc}
\hline \multirow{2}{*}{ Sampling Plots 2013 } & \multicolumn{2}{c}{ P1 } & \multicolumn{2}{c}{ P2 } & \multicolumn{2}{c}{ P3 } \\
\cline { 2 - 7 } & IL & PI & IL & PI & IL & PI \\
\hline Pruning Area & 7 & 1.14 & 8 & 1.75 & 18 & 1.45 \\
Area of Influence of Pruning Area & 15 & 1.27 & 11 & 1.36 & 21 & 1.33 \\
Control Area & 15 & 1.14 & 17 & 1.53 & 30 & 1.54 \\
Area of Influence of Control Area & 18 & 1.28 & 20 & 1.20 & 27 & 1.48 \\
\hline
\end{tabular}

Table 4. Statistical comparison of the Population Intensity recorded in 2012 with respect to those of 2013 in the whole of the areas sampled at each sampling plot (P1, P2, and P3). Z = Value of the statistic for the Mann-Whitney $U$ test; $P=$ Probability $(\alpha \leq 0.05)$.

\begin{tabular}{ccccccc}
\hline \multirow{2}{*}{ Sampling Plots Comparative 2012-2013 } & \multicolumn{2}{c}{ P1 } & \multicolumn{2}{c}{ P2 } & \multicolumn{2}{c}{ P3 } \\
\cline { 2 - 7 } & $\mathbf{P}$ & $\mathbf{Z}$ & $\mathbf{P}$ & $\mathbf{Z}$ & $\mathbf{P}$ & $\mathbf{Z}$ \\
\hline Pruning Area & 0.842 & -0.200 & 0.671 & -0.424 & 0.192 & -1.303 \\
Area of Influence of Pruning Area & 0.559 & -0.585 & 0.636 & -0.474 & 0.407 & -0.828 \\
Control Area & 0.239 & -1.179 & 0.163 & -1.395 & 0.386 & -0.867 \\
Area of Influence of Control Area & 0.098 & -1.655 & 0.570 & -0.568 & 0.375 & -0.888 \\
\hline
\end{tabular}

The comparison of the values of the verisimilitude log and the information criteria (Table A5) did not reveal a good fit again, so no relationship between IL and IP could be stated.

\subsection{Incidence of Coraebus florentinus Five Years after Selective Pruning: Long-Term Infestation}

In the spring of 2017, five years after pruning, the IL and the PI were again evaluated (Table 5). Comparing the ILs in the pruning areas with respect to the control areas, the values continued to be substantially lower in the pruned areas (almost 50\% fewer damaged trees). This trend was evident in the three sampling plots and also manifested in the respective areas of influence.

Table 5. Values of Infestation Level (IL) in \%, and Population Intensity (PI) in average number of dry branches/tree, corresponding to each sampling area established inside each sampling plot (P1, P2, and P3) in 2017.

\begin{tabular}{ccccccc}
\hline \multirow{2}{*}{ Sampling Plots 2017 } & \multicolumn{2}{c}{ P1 } & \multicolumn{2}{c}{ P2 } & \multicolumn{2}{c}{ P3 } \\
\cline { 2 - 7 } & IL & PI & IL & PI & IL & PI \\
\hline Pruning Area & 5 & 1 & 8 & 1 & 15 & 1.07 \\
Area of Influence of Pruning Area & 7 & 1.29 & 10 & 1.40 & 14 & 1.21 \\
Control Area & 11 & 1.09 & 13 & 1.46 & 28 & 1.46 \\
Area of Influence of Control Area & 13 & 1.31 & 15 & 1.07 & 25 & 1.48 \\
\hline
\end{tabular}

Regarding the PIs, as had happened in previous comparisons, there was no statistical significance in any of the cases, neither among sampling plots $\left(P=0.254 ; x^{2}=2.740 ; \alpha \leq 0.05\right)$ nor among areas within each sampling plot (P1: $P=0.477, x^{2}=2.490$; P2: $P=0.129, x^{2}=5.663$; P3: $\left.P=0.123, x^{2}=5.777\right)$. Five years after treatment, comparison of the initial situation (2012) with respect to the current one (2017) revealed noticeable differences in ILs between the pruning areas and their respective areas of 
influence. In the control areas and their perimeters, the ILs were generally maintained, with some slightly oscillations (Tables 2 and 5). The statistical comparison of the PIs in the different areas and sampling plots did not reveal significant differences attributable to the pruning treatment (Table 6).

Finally, as the information criteria are greater than the value of the verisimilitude log (Table A5), no relation between the population indices (IL and IP) could be asserted.

Table 6. Statistical comparison of the Population Intensity recorded in 2012 with respect to those of 2017 in the whole of the areas sampled at each sampling plot (P1, P2, and P3). Z = Value of the statistic for the Mann-Whitney $U$ test; $P=$ Probability $(\alpha \leq 0.05)$.

\begin{tabular}{ccccccc}
\hline \multirow{2}{*}{ Sampling Plots Comparative 2012-2017 } & \multicolumn{2}{c}{ P1 } & \multicolumn{2}{c}{ P2 } & \multicolumn{2}{c}{ P3 } \\
\cline { 2 - 7 } & $\mathbf{P}$ & $\mathbf{Z}$ & $\mathbf{P}$ & $\mathbf{Z}$ & $\mathbf{P}$ & Z \\
\hline Pruning Area & 0.347 & -0.941 & 0.063 & -1.861 & 0.218 & -1.233 \\
Area of Influence of Pruning Area & 0.572 & -0.565 & 0.549 & -0.600 & 0.983 & -0.021 \\
Control Area & 0.189 & -1.314 & 0.411 & -0.822 & 0.375 & -0.887 \\
Area of Influence of Control Area & 0.130 & -1.516 & 0.147 & -1.449 & 0.652 & -0.452 \\
\hline
\end{tabular}

\section{Discussion}

After the first assessment performed in 2012, the level of damage from C. florentinus was determined to be low to medium in the research area. This is consistent with its description as a primary pest of medium importance given its ability to cause growth loss affecting tree canopy shape and not resulting in tree death [8]. Nevertheless, in recent decades the geographical range and damage records of $C$. florentinus have expanded northwardly as a result of global warming [20], and of the heliophilia and thermophilia of the insect [2,21]. Warming conditions are linked to higher reproduction rates and quicker development [1]. In this way, rising temperatures are causing immigration of oak borers toward Central Europe, so much so that $C$. florentinus has recently been included among the wood borer species involved in oak declines in Europe [22].

The spread of the insect, future climate scenarios, and the reduction of oak fitness by water stress can increase damage in forests [20], particularly if reproduction of the beetle occurs in mass [23]. A similar effect has been described for other species of buprestids, such as Agrilus biguttatus, and the implication of this species for acute oak (mainly Quercus robur and Q. petraea) decline has been recently evidenced [24].

Returning to the species under consideration, and particularising for the study area, historical series of data referring to the levels of damage by $C$. florentinus in the Hornachuelos Natural Park are available, which rated the level of infestation between $3 \%$ and $8 \%[5,25]$, while the data obtained in our initial evaluation ranged between $10 \%$ and $34 \%$. This increase confirms the foreseeable upward trend in the population size of this wood borer beetle.

Regardless of the damage caused by C. florentinus, strategies for controlling its populations are scarce or non-existent (see the introduction section), and silvicultural management by pruning damaged branches is the main option employed $[8,26]$. In fact, the same authors proposed monitoring the biology of the insect in the southern Iberian Peninsula, studying also the economic costs of mechanical control by pruning in a "dehesa" with $87 \%$ infestation. A year after pruning, the authors indicated that the reduction in the number of affected trees was near 50\% (agreeing with our results), thus showing that the effects perpetuated in the residual population responsible for subsequent invasion or re-infestation [5]. The authors carried out the pruning at the beginning of July and proposed applying the technique again, at the same time, in the following two years. However, they did not follow the results on a long-term basis.

Keeping in mind all the information available, the starting point of our research was that pruning is the most suitable procedure to control the populations of $C$. florentinus, but we tried to improve the procedure by introducing the innovation of "selective pruning". Selective pruning is the process of selecting individual branches to be pruned. It provides different benefits for the tree, making 
it a recommendable management technique, because it stimulates plant growth, removes diseased structures, can make the tree less attractive to pests, and changes the plant's resistance to pests [27], in addition to destroying weed hosts and serving as an effective control tool [28]. In relation to this last concern, we assessed selective pruning as a method for controlling damage by C. florentinus, but we applied the concept of "selection" with a double meaning: first, selection of branches to be pruned (exclusively the branches that show clear symptoms of suffering a recent attack), and second, selection of the optimal time to prune.

Our results indicate that selective pruning is an effective method to reduce the populations of C. florentinus. In relation to the course of damage after five years of treatment, comparison of the initial situation with respect to the current one revealed remarkable reduction in the level of infestation of the pruning areas and their respective areas of influence, while in the control areas and their perimeters, the infestation was similar to the initial infestation, with some slightly increased and some slightly reduced. In short, our data support the idea that the pruning procedure is also effective at least five years after applying the treatment. Moreover, the effectiveness of this control measure seems to be independent of the degree of attack. In fact, the ratio of affected branches was reduced by half in the three studied plots, even though the plots had different initial levels of damage. A similar reduction was observed in areas with a great number of damaged trees [5]. At first, it would be expected that the greater the infestation, the greater the achieved reduction after pruning. This did not occur when comparing our data with those of a study by Fernández de Cordova and Cabezuelo [5], which can be explained in terms of the effectiveness of pruning; adequate planning of the pruning time optimises the result, even at low levels of infestation.

When indiscriminate pruning is carried out, dry branches resulting from the attacks of previous years are also eliminated. These branches, from which adults have already emerged, do not represent any additional risk; contrarily, the dry branches become a main trophic resource for many saproxylic organisms [16,29-31]. These organisms play a key ecological role in forest ecosystems, contributing to the maintenance of trophic chains [32], favouring decomposition and recycling of plant matter, and contributing to plant pollination [33], which is of particular relevance for maintaining the biodiversity of Mediterranean woodlands [32,34-36].

Thus, it makes no sense to prune the branches after adults have emerged, because no action is being taken against infestation but forest resources are being removed. Hence the need to adjust field tasks to the particular meteorological conditions of each year, which can be done according to the predictive model developed in previous research [1].

Aside from selecting the branches and the pruning time appropriately, we propose cutting and eliminating the portion of the branch that contains the pupation chamber and leaving the rest in the place of origin in order to conserve forest resources. Considering that the duration of the larval development of $C$. florentinus can extend for two or three years, it would be advisable to repeat the selective pruning treatment for at least two consecutive years until the populations of the insect are maintained at lower levels.

\section{Conclusions}

- $\quad$ Selective pruning of branches affected by C. florentinus is an effective method for controlling the populations of this insect, reducing the IL by up to $50 \%$.

- $\quad$ To be most effective, pruning must be scheduled to take place before the emergence of adults, following the predictive models of emergence depending on inter-annual temperature variations.

- This method of mechanical control is effective in both the short and long term, and the population reduction is appreciable not only in the pruned zone but also in the adjacent area.

- The effectiveness of this control measure is independent of the IL by C. florentinus in the managed area. 
- $\quad$ The proven effectiveness of selective pruning to control this species warrants its inclusion among the management activities in Mediterranean oak forests as a preventive measure to avoid the foreseeable demographic explosion due to climate change.

Acknowledgments: We would like to thank ACUAVIR (Environmental Ministry, Government of Spain) for financially supporting this research.

Author Contributions: P.G. and A.M.C. conceived and designed the experiments; P.G. and J.M.S. performed the experiments; P.G., A.M.C. and J.M.S. analysed the data and contributed analysis tools; P.G. and A.M.C. wrote the paper.

Conflicts of Interest: The authors declare no conflict of interest. The founding sponsors had no role in the design of the study; in the collection, analyses, or interpretation of data; in the writing of the manuscript, and in the decision to publish the results.

\section{Appendix A}

Table A1. Environmental features of each of the selected areas in P1 with specific regard to land (surface, orography, orientation, and altitude) and vegetation (vegetal composition and coverage, tree density, woodland age, and average level of damage by C. florentinus) characteristics.

\begin{tabular}{|c|c|c|}
\hline \multicolumn{3}{|c|}{ P1 } \\
\hline & Selective Pruning Area & Area of Influence \\
\hline \multicolumn{3}{|c|}{ Land } \\
\hline Surface & $1.82 \mathrm{ha}$ & 1.54 ha \\
\hline Orography & Hillside with medium slope & Hillside with variable slope \\
\hline Orientation & South & South \\
\hline Altitude & $426 \mathrm{~m}$ above sea level & $426 \mathrm{~m}$ above sea level \\
\hline \multicolumn{3}{|c|}{ Vegetation } \\
\hline Shrubland composition & $\begin{array}{c}\text { Cistus sp. L., Phlomis purpurea L., } \\
\text { Lavandula stoechas L., Rubus ulmifolius Schott, } \\
\text { Daphne gnidium L. }\end{array}$ & $\begin{array}{c}\text { Cistus sp. L., P. purpurea L., L. stoechas, } \\
\text { R. ulmifolius, D. gnidium, Genista hirsuta Vahl., } \\
\text { Pistacia lentiscus L. }\end{array}$ \\
\hline Canopy Cover Fraction & $5-25 \%$ & $50-75 \%$ \\
\hline Woodland composition & Quercus ilex L. (80\%), Q. suber L. (20\%) & Q. ilex $(87 \%)$, Q. suber $(13 \%)$ \\
\hline Average tree density & 76 trees/ha & 57 trees/ha \\
\hline Average tree age & $\begin{array}{c}\text { Mature trees } \\
\text { (average } \varnothing=36.1 \pm 14.5 \mathrm{~cm} \text { ) }\end{array}$ & $\begin{array}{l}\text { Mature trees } \\
\text { (average } \varnothing=36.04 \pm 1.52 \mathrm{~cm} \text { ) }\end{array}$ \\
\hline Average level of damage & $14.6 \%$ & $14.6 \%$ \\
\hline & Control Area & Area of Influence \\
\hline \multicolumn{3}{|c|}{ Land } \\
\hline Surface & $2.05 \mathrm{ha}$ & $1.96 \mathrm{ha}$ \\
\hline Orography & Valley/hillside with variable slope & Valley/hillside with variable slope \\
\hline Orientation & North/no dominant orientation & South/no dominant orientation \\
\hline Altitude & $451 \mathrm{~m}$ above sea level & $451 \mathrm{~m}$ above sea level \\
\hline \multicolumn{3}{|c|}{ Vegetation } \\
\hline Shrubland composition & $\begin{array}{l}\text { Cistus sp., P. purpurea, R. ulmifolius, } \\
\text { D. gnidium, P. lentiscus, } \\
\text { Crataegus monogyna Jacq. }\end{array}$ & $\begin{array}{c}\text { Cistus sp., L. stoechas, P. purpurea, R. ulmifolius, } \\
\text { G. hirsuta, P. lentiscus, C. monogyna }\end{array}$ \\
\hline Canopy Cover Fraction & $5-25 \%$ & $5-25 \%$ \\
\hline Woodland composition & Q. ilex $(72 \%)$, Q. suber $(28 \%)$ & Q. ilex $(80 \%)$, Q. suber $(20 \%)$ \\
\hline Average tree density & 55 tress/ha & 59 trees/ha \\
\hline Average tree age & $\begin{array}{c}\text { Mature trees } \\
\text { (average } \varnothing=44.24 \pm 20.20 \mathrm{~cm} \text { ) }\end{array}$ & $\begin{array}{c}\text { Mature trees } \\
\text { (average } \varnothing=42.46 \pm 17.26 \mathrm{~cm} \text { ) }\end{array}$ \\
\hline Average level of damage & $14.6 \%$ & $14.6 \%$ \\
\hline
\end{tabular}


Table A2. Environmental features of each selected areas in P2 with specific regard to land (surface, orography, orientation, and altitude) and vegetation (vegetal composition and coverage, tree density, woodland age, and average level of damage by $C$. florentinus) characteristics.

\begin{tabular}{|c|c|c|}
\hline \multicolumn{3}{|c|}{ P2 } \\
\hline & Selective Pruning Area & Area of Influence \\
\hline \multicolumn{3}{|c|}{ Land } \\
\hline Surface & 1.14 ha & 1.59 ha \\
\hline Orography & Hillside with low/medium slope & Hillside with medium slope \\
\hline Orientation & South & South \\
\hline Altitude & $541 \mathrm{~m}$ above sea level & $541 \mathrm{~m}$ above sea level \\
\hline \multicolumn{3}{|c|}{ Vegetation } \\
\hline Shrub composition & $\begin{array}{c}\text { Cistus sp., P. purpurea, R. ulmifolius, } \\
\text { D. gnidium, G. hirsuta, P. lentiscus, } \\
\text { Hedera helix L. }\end{array}$ & $\begin{array}{l}\text { Cistus sp., P. purpurea, L. stoechas, R. ulmifolius, } \\
\text { D. gnidium, G. hirsuta, P. lentiscus, Smilax aspera L., } \\
\text { Rosmarinus officinalis L., Nerium oleander L. }\end{array}$ \\
\hline Canopy Cover Fraction & $5-25 \%$ & $25-50 \%$ \\
\hline Woodland composition & $\begin{array}{l}\text { Q. ilex }(95 \%), \text { Q. suber }(3 \%), \\
\text { Q. faginea Lam. }(2 \%)\end{array}$ & Q. ilex (72\%), Q. suber (25\%), Q. faginea (3\%) \\
\hline Average tree density & 71 trees/ha & 120 trees $/$ ha \\
\hline Average tree age & $\begin{array}{c}\text { Young trees } \\
(\text { average } \varnothing=25.74 \pm 11.30 \mathrm{~cm})\end{array}$ & $\begin{array}{c}\text { Young trees } \\
\text { (average } \varnothing=23.89 \pm 12.02 \mathrm{~cm} \text { ) }\end{array}$ \\
\hline Average level of damage & $17.6 \%$ & $17.6 \%$ \\
\hline & Control Area & Area of Influence \\
\hline \multicolumn{3}{|c|}{ Land } \\
\hline Surface & $1.23 \mathrm{ha}$ & 1.32 ha \\
\hline Orography & Valley with low slope & Hillside with low slope \\
\hline Orientation & No dominant orientation & No dominant orientation \\
\hline Altitude & $511 \mathrm{~m}$ above sea level & $511 \mathrm{~m}$ above sea level \\
\hline \multicolumn{3}{|c|}{ Vegetation } \\
\hline Shrubland composition & $\begin{array}{l}\text { Cistus sp., P. purpurea, L. stoechas, } \\
\text { G. hirsuta, Scirpus holoschoenus L. }\end{array}$ & $\begin{array}{c}\text { Cistus sp., L. stoechas, P. purpurea, G. hirsuta, } \\
\text { D. gnidium, S. holoschoenus }\end{array}$ \\
\hline Canopy Cover Fraction & $25-50 \%$ & $5-25 \%$ \\
\hline Woodland composition & Q. ilex (70\%), Q. suber (30\%) & Q. ilex (65\%), Q. suber (35\%) \\
\hline Average tree density & 51 tress/ha & 49 trees/ha \\
\hline Average tree age & $\begin{array}{c}\text { Mature trees } \\
\text { (average } \varnothing=35.99 \pm 14.57 \mathrm{~cm} \text { ) }\end{array}$ & $\begin{array}{c}\text { Mature trees } \\
\text { (average } \varnothing=41.84 \pm 18.25 \mathrm{~cm} \text { ) }\end{array}$ \\
\hline Average level of damage & $17.6 \%$ & $17.6 \%$ \\
\hline
\end{tabular}

Table A3. Environmental features of each selected areas in P3 with specific regardto land (surface, orography, orientation, and altitude) and vegetation (vegetal composition and coverage, tree density, woodland age, and average level of damage by C. florentinus) characteristics.

\begin{tabular}{ccc}
\hline & \multicolumn{2}{c}{ P3 } \\
\hline & Selective Pruning Area & Area of Influence \\
\hline Surface & 1.05 ha & 1.25 ha \\
\hline Orography & Valley & Valley \\
\hline Orientation & No dominant orientation & No dominant orientation \\
\hline Altitude & $206 \mathrm{~m}$ above sea level & $206 \mathrm{~m}$ above sea level \\
\hline
\end{tabular}


Table A3. Cont.

\begin{tabular}{|c|c|c|}
\hline \multicolumn{3}{|c|}{ P3 } \\
\hline & Selective Pruning Area & Area of Influence \\
\hline \multicolumn{3}{|c|}{ Vegetation } \\
\hline Shrubland composition & $\begin{array}{l}\text { Cistus sp., P. purpurea, D. gnidium, G. hirsuta, } \\
\text { G. cinerea Vill., Retama sphaerocarpa L., } \\
\text { P. lentiscus, P. terebinthus L., Asparagus sp. L. }\end{array}$ & $\begin{array}{l}\text { Cistus sp., P. purpurea, D. gnidium, G. hirsuta, } \\
\text { G. cinerea, R. sphaerocarpa, } \text { P. lentiscus, } P \text {. terebinthus, } \\
\text { Asparagus sp., Phillyrea angustifolia L. }\end{array}$ \\
\hline Canopy Cover Fraction & $75-100 \%$ & $75-100 \%$ \\
\hline Woodland composition & Q. ilex $(100 \%)$ & Q. ilex $(100 \%)$ \\
\hline Average tree density & 86 trees $/$ ha & 89 trees $/ \mathrm{ha}$ \\
\hline Average tree age & $\begin{array}{c}\text { Mature trees } \\
\text { (average } \varnothing=34.74 \pm 7.69 \mathrm{~cm} \text { ) }\end{array}$ & $\begin{array}{c}\text { Mature trees } \\
\text { (average } \varnothing=31.62 \pm 9.15 \mathrm{~cm} \text { ) }\end{array}$ \\
\hline Average level of damage & $33.5 \%$ & $33.5 \%$ \\
\hline & Control Area & Area of Influence \\
\hline \multicolumn{3}{|c|}{ Land } \\
\hline Surface & 1.24 ha & 1.36 ha \\
\hline Orography & Valley & Valley \\
\hline Orientation & No dominant orientation & No dominant orientation \\
\hline Altitude & $197 \mathrm{~m}$ above sea level & $197 \mathrm{~m}$ above sea level \\
\hline \multicolumn{3}{|c|}{ Vegetation } \\
\hline Shrubland composition & $\begin{array}{l}\text { Cistus sp., P. purpurea, Asparagus sp., } \\
\text { G. hirsuta, P. lentiscus, P. terebinthus, } \\
\text { P. angustifolia }\end{array}$ & $\begin{array}{c}\text { Cistus sp., P. purpurea, Asparagus sp., G. hirsuta, } \\
\text { D. gnidium, R. sphaerocarpa, P. lentiscus, } \\
\text { P. terebinthus, P. angustifolia }\end{array}$ \\
\hline Canopy Cover Fraction & $75-100 \%$ & $75-100 \%$ \\
\hline Woodland composition & Q. ilex $(100 \%)$ & Q. ilex $(100 \%)$ \\
\hline Average tree density & 79 trees / ha & 82 trees $/$ ha \\
\hline Average tree age & $\begin{array}{c}\text { Young trees } \\
\text { (average } \varnothing=26.03 \pm 8.02 \mathrm{~cm} \text { ) }\end{array}$ & $\begin{array}{c}\text { Young trees } \\
\text { (average } \varnothing=25.72 \pm 7.86 \mathrm{~cm} \text { ) }\end{array}$ \\
\hline Average level ofdamage & $33.5 \%$ & $33.5 \%$ \\
\hline
\end{tabular}

Table A4. Maximum, minimum, and average environmental temperatures $\left({ }^{\circ} \mathrm{C}\right)$ recorded in the study area during the selective pruning period in 2012.

\begin{tabular}{cccc}
\hline Date (DD-MM-YYYY) & Maximum Temperature & Minimum Temperature & Average Temperature \\
\hline $01-04-2012$ & 21.7 & 10.7 & 15.3 \\
$02-04-2012$ & 19.0 & 12.1 & 14.6 \\
$03-04-2012$ & 18.9 & 11.8 & 13.9 \\
$04-04-2012$ & 16.5 & 11.5 & 13.7 \\
$05-04-2012$ & 18.8 & 7.5 & 12.6 \\
$06-04-2012$ & 14.7 & 4.9 & 9.3 \\
$07-04-2012$ & 18.9 & 6.0 & 12.1 \\
$08-04-2012$ & 23.3 & 5.3 & 14.5 \\
$09-04-2012$ & 28.7 & 8.4 & 18.6 \\
$10-04-2012$ & 21.7 & 10.6 & 16.4 \\
$11-04-2012$ & 21.3 & 10.2 & 15.8 \\
$12-04-2012$ & 19.3 & 10.4 & 14.1 \\
$13-04-2012$ & 19.9 & 9.1 & 14.5 \\
$14-04-2012$ & 18.9 & 10.0 & 13.2 \\
$15-04-2012$ & 17.8 & 7.5 & 12.0 \\
$16-04-2012$ & 19.5 & 7.2 & 13.6 \\
$17-04-2012$ & 24.8 & 6.0 & 15.3 \\
$18-04-2012$ & 20.3 & 10.6 & 15.0 \\
$19-04-2012$ & 20.3 & 11.3 & 15.3 \\
$20-04-2012$ & 21.1 & 11.1 & 16.3 \\
\hline
\end{tabular}


Table A4. Cont.

\begin{tabular}{cccc}
\hline Date (DD-MM-YYYY) & Maximum Temperature & Minimum Temperature & Average Temperature \\
\hline $21-04-2012$ & 24.3 & 9.7 & 17.1 \\
$22-04-2012$ & 24.9 & 12.1 & 18.2 \\
$23-04-2012$ & 25.2 & 8.6 & 16.7 \\
$24-04-2012$ & 24.3 & 11.0 & 17.1 \\
$25-04-2012$ & 22.7 & 7.9 & 15.6 \\
$26-04-2012$ & 23.2 & 13.7 & 17.5 \\
$27-04-2012$ & 21.6 & 14.0 & 17.4 \\
$28-04-2012$ & 17.8 & 9.1 & 12.9 \\
$29-04-2012$ & 14.1 & 8.7 & 10.6 \\
$30-04-2012$ & 17.7 & 6.7 & 12.1 \\
\hline
\end{tabular}

Table A5. Verisimilitude log values and Akaike (AIC) and Bayesian (BIC) information criteria obtained in the Generalized Lineal Mixed Model (GLMM) analysis.

\begin{tabular}{cccccccccc}
\hline Years & \multicolumn{3}{c}{$\mathbf{2 0 1 2}$} & & & $\mathbf{2 0 1 3}$ & \multicolumn{2}{c}{$\mathbf{2 0 1 7}$} \\
\hline Plots & P1 & P2 & P3 & P1 & P2 & P3 & P1 & P2 & P3 \\
\hline Verisimilitude Log & 17.44 & 15.10 & 19.02 & 19.20 & 20.10 & 20.10 & 17.67 & 16.71 & 21.62 \\
AIC & 23.44 & 21.10 & 25.02 & 25.21 & 26.10 & 26.10 & 23.67 & 22.71 & 27.62 \\
BIC & 18.54 & 16.20 & 20.12 & 20.31 & 21.20 & 21.20 & 18.77 & 17.81 & 22.72 \\
\hline
\end{tabular}

\section{References}

1. Cárdenas, A.M.; Gallardo, P. The effect of temperature on the preimaginal development of the Jewel beetle Coraebus florentinus (Coleoptera: Buprestidae). Eur. J. Entomol. 2012, 109, 21-28. [CrossRef]

2. Cobos, A. Fauna Ibérica de Coleópteros Bupréstidos; Consejo Superior de Investigaciones Científicas: Madrid, Spain, 1986.

3. Jurc, M.; Bojovic, S.; Komjanc, B.; Krč, J. Xylophagous entomofauna in branches of oaks (Quercus spp.) and its significance for oak health in the Karst region of Slovenia. Biologia 2009, 64, 130-138. [CrossRef]

4. Fürstenau, B.; Rosell, G.; Guerrero, A.; Quero, C. Electrophysiological and behavioral responses of the black-banded oak borer, Coroebus florentinus, to conspecific and host-plant volatiles. J. Chem. Ecol. 2012, 38, 378-388. [CrossRef] [PubMed]

5. Fernández de Cordova, J.; Cabezuelo, P. La "seca de ramillas" o "banderas" de la encina (Coroebusflorentinus Herbst). Distribución biológica y lucha mecánica en la provincia de Córdoba. Phytoma Esp. 1995, 71, 31-37.

6. Kenis, M.; Hilszczanski, J. Natural enemies of Cerambycidae and Buprestidae infesting living trees. In Bark and Wood Boring Insects in Living Trees in Europe, a Synthesis; Lieutier, F., Day, K.R., Battisti, A., Gregoire, J.C., Evans, F.H., Eds.; Kluwer Academic Publishers: Dordrecht, The Netherlands, 2004; pp. 475-498.

7. Lombardero, M.J.; Fernández de Ana Magán, F.J. Distribución y daños de Coroebus florentinus (Herbst) (Col., Buprestidae) en Galicia (NO de la Península Ibérica). Ecología 1996, 10, 499-508.

8. Evans, H.F.; Moral, L.G.; Pajares, J.A. Biology, ecology and economic importance of Buprestidae and Cerambycidae. In Bark and Wood Boring Insects in Living Trees in Europe, a Synthesis; Lieutier, F., Day, R.K., Battisti, A., Gregoire, J.C., Evans, F.H., Eds.; Kluwer Academic Publishers: Dordrecht, The Netherlands, 2004; pp. 447-474.

9. Cárdenas, A.M.; Gallardo, P. The effects of oviposition site on the development of the wood borer Coraebus florentinus (Coleoptera: Buprestidae). Eur. J. Entomol. 2013, 110, 135-144. [CrossRef]

10. Pinilla, R. Plan de Ordenación de Recursos Naturales. Plan Rector de Uso y Gestión del Parque Natural de la Sierra de Hornachuelos; Consejería de Medio Ambiente, Junta de Andalucía: Sevilla, Spain, 2006.

11. Gallardo, P.; Cárdenas, A.M.; Gaju, M. Ocurrence of Reticulitermes grassei (Isoptera: Rhinotermitidae) on cork oaks in the southern Iberian Peninsula: Identification, description and incidence of damage. Sociobiology 2010, 56, 675-687. 
12. Gallardo, P. Incidencia de Coleópteros Perforadores en Formaciones de Quercíneas del Suroeste Peninsular: Evaluación de Daños y Propuestas Para la Conservación. Ph.D. Thesis, University of Córdoba, Córdoba, Spain, 2011.

13. Estaciones Agroclimáticas. Instituto de Investigación Y Formación Agraria Y Pesquera. Consejería de Agricultura Y Pesca. Junta de Andalucía. Available online: www.juntadeandalucia.es/agriculturaypesca/ ifapa (accessed on 25 November 2017).

14. Rodrigo, R.; Herranz, J.L. Actas de Reunión del Acuerdo de Encomienda de Gestión entre la Administración General del Estado, Ministerio de Medio Ambiente (Dirección General para la Biodiversidad-DGB) y el Consejo Superior de Investigaciones Científicas (CSIC) para el control biorracional de plagas del Género. Coraebus 2006, 85, 15.

15. Solinas, M. Considerazioni ecologiche sul preoccupante sviluppo di Coroebus florentinus (Herbst) nelle leccete del Gargano. Entomologica 1971, 7, 115-121.

16. Brechtel, F.; Kostenbader, H. Die Pracht- und Hirschkäfer Baden-Württembergs; Ulmer: Stuttgart, Germany, 2002.

17. Zar, J.H. Biostatistical Analysis, 5th ed.; Prentice Hall: Upper Saddle River, NJ, USA, 1999. Available online: http:/ / www.usgr.com/soil-sterilization (accessed on 8 November 2017).

18. Bolker, B.M.; Brooks, M.E.; Clark, C.J.; Geange, S.W.; Poulsen, J.R.; Stevens, M.H.H.; White, J.S.S. Generalized linear mixed models: A practical guide for ecology and evolution. Trends Ecol. Evol. 2008, 24, 127-135. [CrossRef] [PubMed]

19. SPSS Inc. SPSS 20.0 for Windows Use Manual (Version 20.0); SPSS Inc.: Chicago, IL, USA, 2011.

20. Buse, J.; Griebeler, E.M.; Niehuis, M. Rising temperatures explain past immigration of the thermophilic oak-inhabiting beetle Coraebus florentinus (Coleoptera: Buprestidae) in south-west Germany. Biodivers. Conserv. 2013, 22, 1115-1131. [CrossRef]

21. Verdugo, A. Fauna de Bupréstidos de la Península Ibérica y Baleares; Argania editio: Barcelona, Spain, 2005.

22. Sallé, A.; Nageleisen, L.M.; Lieutier, F. Bark and wood boring insects involved in oak declives in Europe: Current knowledge and future prospects in a context of climate change. For. Ecol. Manag. 2014, 328, 79-93. [CrossRef]

23. Hellrigl, K. Faunistik der Prachtkäfer von Südtirol (Coleoptera: Buprestidae). For. Obs. 2010, 5, $153-206$.

24. Reed, K.; Denman, S.; Leather, S.R.; Forster, J.; Inward, J.G. The lifecycle of Agrilus biguttatus: The role of temperature in its development and distribution, and implications for Acute Oak Decline. Agric. For. Entomol. 2017. [CrossRef]

25. Soria, F.J.; Ocete, M. Estudios poblacionales sobre Coroebus florentinus (Herbst) (Col. Buprestidae). Boletín de Sanidad Vegetal Plagas 1993, 19, 27-35.

26. Tiberi, R.; Branco, M.; Bracalini, M.; Croci, F.; Panzavolta, T. Cork oak pests: A review of insect damage and management. Ann. For. Sci. 2016, 73, 219-232. [CrossRef]

27. O'Connor-Marer, P.J. Landscape Maintenance Pest Control (Pesticide Application Compendium); ANR Communication Services, University of California: Oakland, CA, USA, 2006.

28. Angelo, M.J. The Law and Ecology of Pesticides and Pest Management; University of Florida Levin College of Law, USA; Routledge Taylor \& Francis Group: London, UK; New York, NY, USA, 2016.

29. Recalde, J.I.; San Martín, A.F. Coleópteros asociados a ramas de Quercus muertas por la acción del bupréstido Coraebus florentinus (Herbst, 1801) en la Navarra media. Heteropterus Rev. Entomol. 2003, 3, 43-50.

30. Niehuis, M. Die Prachtkäfer in Rheinland-Pfalz und im Saarland; GNOR-Eigenverlag: Mainz, Germany, 2004.

31. Gallardo, P.; Cárdenas, A.M. Long-term monitoring of saproxylic beetles from Mediterranean oak forests: An approach to the larval biology of the most representative species. J. Insect Conserv. 2016, 20, 1-11. [CrossRef]

32. Schlaghamersky, J. Saproxylic invertebrates of foodplains, a particular endangered component of biodiversity. In Proceedings of the International Symposium Dead Wood: A Key to Biodiversity; Mason, F., Nardi, G., Tisato, M., Eds.; Mantova, Compagnia delle Foreste: Arezzo, Italy, 2003; pp. 15-80.

33. Davies, Z.G.; Tyler, C.; Stewart, G.B.; Pullin, A.S. Are current management recommendations for saproxylic invertebrates effective? A systematic review. Biodivers. Conserv. 2008, 17, 209-234. [CrossRef]

34. Dajoz, R. Entomología Forestal: Los Insectos y el Bosque; Mundi-Prensa: Madrid, Spain, 2001. 
35. Bouget, C.; Brustel, H.; Zagatti, P. The French information system on saproxylic beetle ecology (FRISBEE): An ecological and taxonomical database to help with the assessment of forest conservation status. Rev. Ecol. Terre Vie 2008, 10, 33-36.

36. Quinto, J. Diversidad, Ecología y Conservación de Insectos Saproxílicos (Coleoptera y Diptera: Syrphidae) en Oquedades Arbóreas del Parque Nacional de Cabañeros (España). Ph.D. Thesis, University of Alicante, Alicante, Spain, 2013.

(c) (i)

(C) 2018 by the authors. Licensee MDPI, Basel, Switzerland. This article is an open access article distributed under the terms and conditions of the Creative Commons Attribution (CC BY) license (http://creativecommons.org/licenses/by/4.0/). 